\title{
Exploring seafood socialization in the kindergarten: An intervention's influence on children's attitudes
}

\begin{abstract}
Purpose - This paper aims to enhance understanding of the influence of increased food availability and social learning in kindergartens on children's attitudes towards food. In addition, it discusses questions regarding children and their parent's attitudes and seafood consumption at home.
\end{abstract}

Design/methodology/approach - The study employs a qualitative approach that includes semi structured interviews with twenty-four Norwegian children aged 4-6 years, interviewed in pairs. They represented two public kindergartens. One group attended a seafood intervention and the other did not. The intervention comprised seafood served as lunch twice per week, in addition to various educational activities designed to increase children's knowledge of seafood.

Findings- Children who attended the seafood intervention used more cognitive associations by describing seafood as healthy. They also expressed more positive attitudes towards seafood compared with the other children. The findings indicate a stronger socialization effect from parents than preschool teachers.

Research limitations/implications- The children proved to have limited cognitive and communicative abilities for participation in semi structured interviews. Future studies should consider older samples and/or methods that are more adapted to their cognitive abilities. Results cannot be generalized due to the relative small sample and performed in one culture.

Social implications- To promote a healthier diet, children's caregivers and school authorities should make seafood more available. Preschool teachers should be encouraged to eat meals with the children in order to function as positive role models.

Originality/value- The study addresses a currently under-researched issue concerning the influence of kindergartens on children's food attitudes towards a specific food category.

Keywords: Modeling, norms, food availability, mere exposure, fish, preschool 
Article Classification- Research paper 


\section{Introduction}

There is significant research regarding how childhood eating habits persist into adulthood (Birch et al, 2007; Marshall and O’Donohoe, 2010). Therefore, a promising strategy to prevent diet-related diseases is to encourage healthy eating habits in childhood. Statistics published by the OECD show that the childhood obesity rate is increasing in most European countries (OECD, 2012). Children and young people are advised to include more vegetables, fruit, whole grains and seafood in their diet. Children eat significantly less seafood than adults. Research indicates that Norwegian children and adolescents consume 140-210 g of seafood per week on average. The recommended consumption is 300-450 g (Norwegian Directorate of Health, 2011). A large portion of this consumption is processed products such as fish dumplings and fish sticks containing small amounts of fish. It has been specifically recommended that children and young people increase their consumption of oily fish, such as salmon, mackerel and herring, due to the benefits of polyunsaturated fat.

In many countries, young children attend public or private kindergartens. For example, in Norway, almost $90 \%$ of all 1-5 year olds attend kindergartens (Statistics Norway, 2012). This implies that food and drink consumed in the kindergarten constitutes a significant part of the children's diets (Norwegian Directorate of Health, 2007; Bernadi et al., 2010). Yet, most research has focused on interventions for school-aged children, while we know little about the effect of interventions made for younger children (Bond et al., 2011). This paper presents an explorative study of an intervention in Norwegian kindergartens that aimed to improve children's knowledge about seafood by both increasing its availability and educating teachers about its health properties (Fiskesprell, 2013). The study examines the influence of such an intervention on children's attitudes towards seafood and addresses the following three research questions: What attitude do children have to seafood (1), how do mere exposure (2) and food socialization influence their attitudes (3)?

\section{Conceptual framework}

Our eating habits are influenced by many interacting factors, such as product characteristics, human biology, physiology, psychology and sociocultural aspects (Köster, 2009). This study uses attitude theory (Ajzen, 2001), norm-theory (Cialdini et al., 1990; Donald and Cooper, 2001) and theories about mere exposure (Zajonc, 1968) to explain the intervention as a social learning process. 
Parents are usually considered to be the most important agents who influence children's diet (Pedersen et al., 2012). Our study integrates parents (home environments) and teachers (preschool environments) into a broader group of agents called caregivers. This paper suggests that increased availability of seafood will influence children's attitudes through mere exposure (Zajonc, 1968; Pliner, 1982). In addition, it advocates that caregivers influence children's attitudes towards food through role modelling and providing norms (Hendy and Raudenbush, 2000). The increased availability of seafood in kindergartens may stimulate caregivers to both communicate its advantages and act as role models. We suggest expanding role modelling by introducing subjective and descriptive norms (Berg et al., 2000; Donald and Cooper, 2001). These concepts are further described.

\section{Children's attitude towards seafood}

Examining food attitudes is one way of exploring the factors that guide food selection (Aikman et al., 2006). Attitudes are defined as the summary of people's cognitive and affective evaluations of objects that guide behaviour towards those objects (Ajzen, 2001). Affect has been explained as the first reaction to objects and occurs independently of perceptual and cognitive encoding (Zajonc, 1980). Research on human's attitudes has traditionally been built on the assumption that knowledge or beliefs affect attitudes which in turn influence behaviour. Therefore changes in behaviour can be brought about by increasing knowledge (Sheperd and Sparks, 1994). However, children’s limited cognitive abilities may limit the effect of attitude change (John, 1999). They have a higher tendency than adults to build their attitudes on affect and hedonistic feelings (Borgers, et al. 2000; Lumeng et al., 2008). This may be a reason why children and young consumers are less concerned about healthy food (Berg et al., 2000; Honkanen et al., 2004).

Aikman et al. (2006) introduce five information bases for food attitudes: positive and negative affect, general and specific sensory qualities, and abstract cognitive qualities. Evaluations of one or more of these information bases determine a person's food attitude. For example, a slightly positive attitude to salmon might reflect a strong positive evaluation of the abstract cognitive quality 'healthiness', but a slightly negative evaluation on the general sensory quality 'taste'. This study was intended to identify children's different informational bases for their attitudes toward seafood.

Few studies have focussed on children's attitudes towards seafood compared to other food categories, such as fruit and vegetables (e.g. Blissett, 2011; Melbye et al., 2012). 
Honkanen et al. (2004) found that Norwegian teenagers aged 14-18 usually preferred dinner options such as pizza, tacos, hamburgers and pasta over seafood. Of the total, 37\% were described as fish haters, while 27\% were categorized as fish lovers. Fish haters also showed little interest in healthy food and practised irregular and unhealthy food habits such as skipping dinner and between-meal snacking. Fish lovers, on the other hand, often preferred salmon and trout over other dinner alternatives and practised more beneficial food habits. Children's food attitudes may also affect the consumption patterns of other family members. Olsen (2001) discovered that children with negative attitudes towards fish had a negative effect on the family's seafood consumption. This may be explained by conflicts between family members. Parents usually want to serve food which they consider healthy, but also that which their children like (Nørgaard and Brunsø, 2011). This situation often results in a health-pleasure trade-off.

\section{Mere exposure}

Caregivers influence children's eating practices by making food available. Several studies have shown that children are more likely to eat food that is available, easily accessible and to which they have been exposed multiple times in various situations (Patrick and Nicklas, 2005). Availability includes food being provided in accessible locations and accessible sizes (e.g. carrot sticks). It also deals with how frequently children are exposed to food. Mere exposure describes different aspects of availability and people’s tendency to prefer familiar stimuli (Zajonc, 1968). Several studies have illustrated mere exposure as prevention for childhood innate food neophobia (e.g.;Wardle et al., 2003b; Busick et al., 2008; AnzmanFrasca et al., 2012. The number of exposures required to alter preferences and attitudes differs according to age, with preteens needing up to twenty times the exposures of infants (Cooke, 2007). Previous studies show that parents have a tendency to "give up" offering children rejected food after five attempts, limiting the effect of mere exposure (Mitchell et al., 2013). Taste exposure and not just visual exposure, is also important (Birch et al., 1987). The importance of availability and mere exposure of seafood is further illustrated in the study by Honkanen et al. (2004) which discovered that fish haters usually had below-average numbers of fish servings at home, while fish lovers had plentiful access to seafood.

\section{Food socialization}

Consumer socialization theory is used to explain the learning processes of children as consumers and buyers in the marketplace (Gaumer et al., 2013). Family food socialization is 
used as a theoretical framework to understand children's eating behaviours on the basis of their caregivers’ preferences, beliefs and attitudes towards food (Nicklas et al., 2001). Other studies use "role modelling" to explain what occurs when children observe and memorize impressions from the environment and when they are motivated and can remember the model behaviour (Ormrod, 2009). In this way, caregivers serve as role models for children's dietary preferences and attitudes as well as helping to overcome food neophobia (Benton, 2004; Birch et al., 2007). This was illustrated in the study by Harper and Sanders (1975) in which children proved more willing to consume unfamiliar food when an adult was eating it, rather than when the food was merely offered to the children.

It is possible to understand role modelling as an analogue to the norm construct in social psychology (Fishbein and Ajzen, 2010). For example, Birch and colleagues (2007) claim that there is consistent evidence that the responsive 'do as I do' approach has a stronger positive effect on children's consumption patterns than the unresponsive 'do as I say' approach. Their findings can be explained by suggesting the difference between subjective and descriptive norms. Subjective norms are the child's beliefs about how others perceived as important expect him or her to act (Berg et al, 2000; Nørgaard et al., 2007). Descriptive norms are the child's perceptions of what others actually do, reflecting the considerations of normal behaviour (Cialdini et al., 1990). They have been argued to exert a less direct, but often more powerful influence because of observational learning (Bandura, 1977). Thus, children's observations of their caregiver's preferences, attitudes and behaviours (descriptive norms) may more strongly influence their feelings and behaviour than their caregiver's expectations (subjective norms). In a study of Vietnamese consumers, Tuu et al. (2008) found that both subjective and descriptive norms explained the intention to consume seafood and emphasized the importance of distinguishing between those different dimensions of norms. Thus, this study determines whether children differentiate between subjective and descriptive norms. This difference can be important for kindergartens when they organize their meals. How important is it for preschool teachers to eat with the children so that they serve as role models, thus providing descriptive norms? This question may also be important for families when organizing meals in daily life.

\section{Methodology}

To our knowledge, no studies using child samples have researched young children's perspectives on seafood. Several researchers have emphasized the importance of allowing 
children to express their views in their own terms and of including them as co-creators in the study design and data collection (Einarsdottir, 2007; Grieg and Taylor, 2007). The most comparable study we found was by Honkanen et al.(2004) on teenagers, and their results are difficult to generalize to younger samples. For instance, young children are much more neophobic towards unfamiliar foods and have less developed cognitive skills than teenagers (Marotz, 2011). For this reason, we chose a qualitative exploratory design for studying an intervention's influence on children's attitudes towards seafood.

\section{The seafood intervention}

Norway provides public recommendations regulating food availability in kindergartens (Norwegian Directorate of Health, 2007). The kindergarten should, for instance, offer minimum of two nutritious daily meals, including breakfast. The meals should include whole grain products, vegetables, fruit, fish, meat, eggs and low-fat milk. Sugary foods should be avoided. It is recommended, but not required, that preschool teachers eat with children.

Half of the data for this study came from a kindergarten participating in the seafood intervention programme called 'Fiskesprell', developed by the Ministry of Health and Care Services, the Ministry of Fisheries and Coastal Affairs and the Norwegian Seafood Council (Fiskesprell, 2013). This is a voluntary project involving Norwegian kindergartens and schools. The intervention aims to increase children's knowledge about seafood and to give them good taste experiences of seafood. Preschool teachers participating in the intervention use seafood and meals for educational activities, such as teaching children the names of the most commercial fish species and demonstrating how to prepare them. Some teachers can join a free course on the intervention implementation in their kindergarten. Other activities include visits to aquariums and teaching children songs about fish and fishing. Children in the kindergarten where the intervention took place were offered seafood meals twice a week, in addition to fish being a regular sandwich spread. The other data came from a kindergarten that did not participate in the intervention. They did not have a fixed seafood plan, but hot meals were served once a week. The study did not measure seafood availability at home, but it documented children's subjective opinion and associations about seafood availability.

\section{Sampling}

The kindergarten in the seafood intervention was selected through convenience sampling, while the other was selected from 10 random, public kindergartens in the city of Tromsø, Norway. The kindergartens received an invitation to participate through e-mail. Our preferred age group was the oldest children in the kindergarten, ages 4-6. This age group is 
particularly interesting for study since they are known for establishing lifelong attitudes to food and health (Marotz, 2011). The study's ethical and confidential aspects followed recommendations from the Norwegian Research Ethics Committee (NSD, 2013). The kindergartens staff helped distribute an informational letter about the study to all guardians with children in the target group. The letter described the study's aim, the methodological approach and how personal information would be stored and used anonymously. Parents who wanted their children to participate returned a consent form to the kindergarten staff. Thus, children participated as a result of volunteer sampling (Morse, 1991). Prior to data collection, children received oral information similar to that sent to parents, but adapted to their age. They were assured that their participation was voluntary and that they could withdraw at any time. The recruitment process resulted in 28 returned consents. Of these, three of the children were not present, and one refused participation on the days scheduled for data collection. The final sample consisted of 24 children, 12 from each kindergarten, with a gender balance of 13 boys and 11 girls.

\section{Data collection}

As a methodological approach, this study used interviews, because they allow children to express their opinions in a manner fitting their cognitive and linguistic competence (Grieg and Taylor, 2007). However, we took some precautions since interviewing children is significantly different than interviewing adults (Irwin and Johnson, 2005). For example, to build the children's trust, prior to data collection, the fieldworker (SA) spent two days as a staff member in each kindergarten (Clark, 2010). Later, the children were interviewed in a closed kindergarten playroom, thus ensuring a familiar setting and eliminating response bias. We chose to interview children in pairs because they could help initiate new ideas, ease the progress of conversation and reduce researcher influence (Owen et al., 1997). No specific requirement was used to pair the children other than who was available and volunteered when SA was ready for interviews. Children were informed that the interview would be voice recorded and that they could listen to the recording after the interview.

The interviews had a semi structured character to ensure that topics of interest were covered. The interview guide included 41 questions, where the number of questions asked depended on the interview process and the responses of the children. Most questions where close-ended, since it put less weight on young children's verbal abilities (Irwin and Johnson, 2005). We used Aikman and colleague's (2006) attitude model for food to identify children's attitudes towards seafood. To determine the influence of preschool teachers as role models, 
we asked the children whether the adults ate with them and whether they thought the adults liked their preferred food. To identify children's perception of subjective norms, we asked them whether their favourite preschool teacher wanted them to eat more fish. The same questions were asked regarding their parents in order to gather information on social influence patterns at home. To identify descriptive norms, we asked them about their beliefs and observations regarding their teachers and parents and if they thought they liked or ate seafood. Since we were aware of the frequency of seafood availability in the kindergarten, we only asked them to elaborate on seafood consumption for dinner at home. SA emphasised that there were no right or wrong answers and that she was genuinely interested in knowing the children's own thoughts. Children were allowed to take small breaks, tell stories and discuss each other's answers during the interview, making the interviews more convenient and adapted to children's age. The interviews lasted an average of 22 minutes. After the interviews were completed, all the informants received a small gift for participating.

\section{Data analysis}

The interviews were transcribed verbatim and then content analysed (Patton, 2002) by SA who conducted the interviews. At the first stage of analysis, transcripts were repeatedly read and studied to identify both pre-determined and emerging themes and patterns. Major topics as well as confusing and conflicting data were discussed amongst the authors. During this process, some themes tended to cluster, identifying data patterns. The next step was to compare data between the two kindergartens by making two sheets, one for each kindergarten. The sheets contained an index with main themes, subthemes and illustrative quotations from the interviews (Ritchie et al., 2005). This approach took the data through a hermeneutic process, allowing exploration in both parts and wholes. Voice recordings were deleted and transcripts were anonymized by the end of the study.

\section{Findings}

This section discusses the findings by comparing the kindergarten with the seafood intervention, called 'intervention group', and the other kindergarten, called 'no-intervention group'. The results related to food socialization and seafood availability involved questions concerning both kindergarten and home environment. Quotations from the interviews have been freely translated into English for the sole purpose of this paper. To protect 
confidentiality, identifying information has been removed. Ellipses in brackets indicate that part of the sentence has been deleted.

\section{Attitudes and associations towards seafood}

Our results indicate that the intervention group had more positive attitudes towards seafood than the other group. In the intervention group, more children preferred seafood for dinner, compared to the other group. Traditional Norwegian processed seafood, such as fish au gratin and fish dumplings, was more preferred than unprocessed products such as salmon or cod fillets. Pancakes and spaghetti were the most preferred dinner option for all children, irrespective of their group. Taste was the most frequent reason cited in explaining their preference.

Interviewer: What do you like the best?

-Fish dumplings are my favourite. It's the best thing on earth.

Interviewer: Why do you like fish dumplings so much?

-My stomach loves it and my bones like it.Boy, aged 5, intervention group

Interviewer: Why do you like pancakes and waffles so much?

-Because what you don't like does not have a good taste, and what you like has a good taste. Boy, aged 4, no-intervention group

Fish smell and appearance were other important attributes that explained the children's preference. While some claimed that fish smelled bad and sometimes had too many bones, several felt that the good taste outweighed the disadvantages. For example, when was asked about fish smell, a 5-year old girl from the intervention group responded, 'I don't like the smell of fried fish, but I do like the taste a bit'.

Our study also showed that children in the intervention group tended to describe food not only by taste or smell but also as healthy and strengthening. Children in the other group had difficulties explaining healthy foods and their effects on the body.

Interviewer: How important is it to eat healthy food?

-It's really important, because you get strong and you manage to walk.

Interviewer: But what is healthy food?

-Fish, chicken and mackerel in tomato sauce on the bread is healthy. Girl, aged 6, intervention group 
Most children in the intervention group could name more fish species than those in the other group. Instead of using proper names, many in the latter group described fish appearance, such as colour and shape.

Interviewer: Is there any fish you like to eat?

-I like the orange fish.

Interviewer: Orange fish...Can it be salmon? (...)

-I don't know. Boy, aged 4, no-intervention group

To evaluate children's preference for seafood, we asked their preference for dinner. Children in the intervention group tended to spontaneously mention seafood compared with the other group. Pancakes and Spaghetti Bolognese were the other popular meals mentioned by most children in both groups.

Interviewer: If you were the boss, what would you have for dinner when you get home today?

-Minced meat with spaghetti... or chicken.

Interviewer: What about fish?

- No, I hate fish!Boy, aged 6, no-intervention group

\section{Seafood exposure}

We asked the children if they were served seafood too often at the kindergarten. Most of the children in the intervention group agreed, while a few disagreed. Some children had problems answering the question. We did not register any differences between children who thought seafood serving was too frequent and those with negative attitudes towards seafood. Children who did not participate in the seafood intervention usually did not have seafood for lunch, and some of them told us they would like to have more seafood in the kindergarten.

Interviewer: Do you think you get too much fish in the kindergarten?

-No, I don't get any fish. We almost never do.Boy, aged 5, no-intervention group

For seafood availability at home, we asked the children how often they had seafood for dinner. The results indicated that even those who claimed to have seafood often for dinner did not necessarily feel it was too often. 
Interviewer: How often do you have fish for dinner at home?

-It's not that often. We usually have some.

Interviewer: Do you wish it was more often?

-Yes. Boy, aged 4, no-intervention group

The interviews indicated that children in the intervention group talked more favourably about specific seafood dishes. Traditional Norwegian dishes with processed seafood such as fish dumplings and fish cakes where often mentioned more favourably than unprocessed seafood such as cod and salmon fillet.

\section{Seafood socialization}

To explore the descriptive (norm) or observational facet of role modelling in kindergartens, we asked the children their favourite preschool teacher and his/her food preference. The answers indicated that no one in the intervention group had any perception about their favourite teacher's food preferences, while some children from the other group did. Questioning the preschool teachers revealed that the adults in the no-intervention group sometimes ate breakfast with the children, while those in the intervention group did not eat any meals with the children.

Interviewer: What do you think is [preschool teacher's] favourite food to eat?

-Sandwich with salami and cucumber. And she likes ham with spice. Girl, aged 5, nointervention group

We explored the subjective or normative (norm) facet of role modelling in the kindergarten by asking if the children thought that their favourite person wanted them to eat seafood. Most children assumed that the person preferred seafood, but had no recollection if that person had any requests for their diet.

Interviewer: Do you think [preschool teacher] wants you to eat more fish?

-No, she just pays attention to see if everybody has eaten their food.Girl, aged 6, intervention group

For the investigation of descriptive norms at home, we asked the children about their parent's preferences for dinner. The results showed that the children had much clearer 
opinions about their parent's preferences and seemed quite aware of the contradicting food preferences. Pancakes were the children's most preferred dinner option, while it was not their parent's. In the intervention group, six children and their fathers preferred seafood for dinner.

Interviewer: How much do you think your mom likes fish for dinner?

-My mom does not like it, but she eats it.

Interviewer: What about your dad? - Yes, that's why he makes salmon for dinner (...).

Mostly when mom is gone and dad takes care of us.Girl, aged 6, intervention group

Subjective norms related to parents were explored by asking children if they thought their parents wanted them to eat seafood; about half of the children answered affirmatively. As expected, no difference existed between the two groups.

Interviewer: Do you think your mom wants you to eat fish for dinner?

-Yes, she does and dad does as well.

Boy, aged 5, intervention group

Our results indicate that children under pressure from parents (subjective norm) had less favourable attitudes towards seafood, compared to those who did not experience pressure. The children who believed that their parents preferred seafood (descriptive norm) had a higher tendency to prefer seafood, compared to other food groups. In our experience, to measure the effect on subjective and descriptive norms was difficult in the kindergarten, since children usually could not observe the preschool teachers during meals.

\section{Summary and discussion}

This study aimed to explore the influence of mere exposure in kindergartens and social learning from preschool teachers on children's attitudes towards seafood. To a minor degree, we also discussed possible influences of their parents' attitudes and seafood availability at home. Theoretical constructs from attitude theory (Ajzen, 2001; Aikman et al., 2006), theory about mere exposure (Zajonc, 1968) and norm-theory (Tuu et al., 2008) were used to extend traditional social learning theory (e.g. role modelling) for food socialization (Nicklas et al., 2001).

With regard to research question 1, or what attitude do children have toward seafood, the results showed that most children had positive attitudes towards seafood, irrespective of their participation in the intervention. Our study indicates that young children may have more 
positive attitudes towards processed seafood, such as fish au gratin and fish dumplings than unprocessed products. These findings correspond with research by the Norwegian Directorate of Health (2011). Several children claimed that they did not like fish, even showing strong aversion, while at the same time expressing that some of their favourite foods for dinner were various processed seafood products. This indicates that the children did not associate processed products with the word fish. A possible implication for caretakers may be to educate children about the specific names of seafood products and dishes and products instead of using the general term fish. In that way, children would be better able to express to their caretakers which specific dishes they like and dislike. In addition, these findings also indicate that caretakers should choose processed seafood products that contain high percentages of fish (Norwegian Directorate of Health, 2011). In our sample, there were less favourable attitudes towards salmon and trout, which contrasted with Honkanen and colleague's (2004) study of older children. A possible explanation may be young children's preferences for the soft textures of processed products (Zeinstra et al., 2007)..

We confirmed our expectations that children, to a much higher degree than adults, have a tendency to build their attitudes on positive and negative affective associations (Borgers et al., 2000; Aikmanet al., 2006; Lumeng et al., 2008). Children with positive attitudes towards seafood explained that eating seafood made them happy, while those who did not like seafood felt disgusted while eating it. Phrases like "I love" and "I hate" was often used. Our sample showed that good taste was the main reason for positive attitudes towards seafood. Most children could describe general sensory qualities such as appearance, flavour and smell, but had problems describing more specific sensory qualities such as oiliness and saltiness. This can be explained by the fact that the children were dependent on their memories to answer interview questions since the study did not involve actual food tasting. In the study on Norwegian teens by Honkanen and colleagues (2004), the smell of fish and the fish bones indicated aversion. In our study, children did not seem much concerned about this. Perhaps younger children's parents may help them pick out the bones or use fillets without bones when cooking seafood for the family.

In research question 2, how does mere exposure influence children's attitude to seafood, we explored the difference between the group with high seafood availability against the group with low seafood availability. Children participating in the seafood intervention tended to associate seafood with abstract cognitive qualities (Aikman et al., 2006). They believed, for example, that seafood could make them strong and healthy. The other group responded with more negative evaluations and focused more on general sensory qualities like 
the taste and smell of seafood (Aikman et al., 2006). Our results do not indicate that children's cognition is more important than their affective associations, but do show that children in the intervention group had more knowledge about seafood, giving them more reasons to eat seafood rather than to respond only with affect (Sheperd and Sparks, 1994). Therefore, we found the intervention group to have the most fish lovers and the other group to have the most fish haters (Honkanen et al. 2004). Future studies are needed to research how this influences the children’s families’ consumption of seafood (Olsen, 2001; Nørgaard and Brunsø, 2011).

Further,, children with high exposure to seafood described a larger variety amongst seafood dishes as their favourite food than the other children. This indicates that mere exposure (Zajonc, 1968; Pliner, 1982) to seafood may have a positive effect on children's attitude development and preventing food neophobia (Busick et al. 2008; Anzman-Frasca et al. 2012). In the study by Wardle and colleagues (2003a), parents in the exposure group reported that their children's daily tasting of previously disliked vegetables increased their willingness to try other novel foods. Thus, the seafood intervention may be a promising strategy for increasing children's consumption of a variety of foods since it involves actual tasting. Our study indicates that the strength of the seafood intervention is its mere exposure effect. By making seafood more available to children, they became more familiar with seafood and were able to taste a variety of it. Children in our study mainly built their attitudes on their taste experiences, stressing the importance of making seafood often availablein the kindergarten.

Finally, research question 3, how does food socialization influence children's attitudes to seafood: the results indicated that preschool teachers functioned as weak role models for observational learning. Since teachers and children usually did not eat together in the kindergarten, children had difficulties expressing opinions about their teachers' preferences. Children could more easily name their parents' favourite food (descriptive norms) because children regularly observed their parents' meals. This corresponds with the findings of Berg and colleagues (2000); children's perceptions of their parents' behaviour exerted more influence over their food consumption. In our study, preschool teachers could only encourage the children to eat seafood (subjective norm) and give them nutritional information without eating seafood themselves. This is described as a less desirable strategy for increasing children's willingness to taste less wanted foods (Wardle et al., 2003b). We agree with Tuu et al. (2008) and Birch et al. (2007) on the importance of distinguishing subjective and descriptive norms and argue that caregivers need to provide both norms to serve as strong role models, a view confirmed by other studies (Benton, 2004; Honkanen et al., 2004). 
We need to acknowledge the important role kindergartens and schools play for the development of children's diet. Most studies on food socialization primarily focus on parents as the social agent for children (e.g. Birch et al., 2007). This study stresses the importance of including other caregivers as social agents for children's food socialization ( Patrick and Nicklas, 2005). Health interventions in schools and kindergartens may cater to many people, but to provide proper food socialization, future authorities and researchers should emphasize the importance of adults eating with children, providing both subjective and descriptive norms. All caregivers must be aware of their responsibilities in providing healthy food for children and their obligation to present themselves as positive role models.

\section{Limitations and implications}

As a qualitative and exploratory study, our findings have multiple limitations. The results cannot be generalized since the study was conducted on a small sample of children in Norway-a country with relatively high seafood consumption (Norwegian Directorate of Health, 2011). Future studies may use larger samples to obtain more representative results and be compared with other cultures with less seafood consumption. The young age and limited cognitive level of the children challenged the study's reliability (Borgers et al., 2000). Sometimes the children had difficulties understanding our questions, so we had to provide examples a process which can lead the informants. Sometimes the children had difficulties concentrating during interviews, especially at the end. Although other researchers have recommended keeping interview duration within 30 minutes (Owen et al., 1997), we recommend using less than 22 minutes for interviewing children younger than six years. Having toys present during the interview seemed more distracting than helpful for keeping the children's attention.

Some children gave contradictory and imaginative answers, making the analytical process challenging. As an example, several children described their favourite fish as yellow, which later proved to be an animated fish they had seen on the Internet. In our experience, traditional interviews may not be beneficial for research involving children this young, since the method are dependent on the informants' memories, communicative abilities and comfort when being interviewed by an adult stranger. The fieldworker's time spend as a kindergarten staff member and allowing children to be interviewed in pairs might have compensated for some of that weakness Future studies which use traditional interviews as a method should consider samples older than 6 years. It is important that the methods are adapted to children's 
cognitive level and involve them actively in the research process (Einarsdóttir, 2007). Good examples are photo interviews (Zartler and Richter, 2012), participant observation (Pramling and Doverborg-Östberg, 1993) and different projective techniques such as the Children's Apperception Test (Bellak and Abrams, 1997) and children’s drawings (Marshall and Atiken, 2007).

The study did not measure children's pre-intervention attitudes to seafood, how many seafood exposures the children had undergone or evaluate the children's actual seafood choices. Therefore, the study does not prove that the intervention changed children's attitudes or caused them to choose to eat seafood (Köster, 2009). Implications for future food interventions are the need to measure children's actual food attitudes and choices before and after the intervention's implementation, as well as how many exposures are needed to change children's attitudes.

Further, we used descriptive and subjective norms to operationalize role modelling as food socialization. These constructs relate closely to parenting style (Block et al., 2011), feeding style (Hughes et al., 2008) and family communication (Moschis, 1985; Schrodt et al., 2008). Quantitative studies are needed to test the validity of the constructs used as well as other constructs which can be classified under food socialization.

Future studies could include more informants, such as parents and teachers, to understand the relative and combined influence from other social agents. Our study indicates stronger food socialization effect in the home. If children are experiencing conflict between norms promoted by kindergartens and schools and the norms of their parents, food interventions will be less effective in improving children's diets. Possibly, food norms in Norway are more unified and differ somewhat from other, more mixed societies like the UK and the USA. Thus, future studies should be conducted in more mixed and varied cultures. 


\section{References}

Aikman, S.N., Crites, S.L. and Fabrigar, L.R. (2006), "Beyond affect and cognition: Identification of the informational bases of food attitudes”, Journal of Applied Social Psychology,Vol. 36 No. 2, pp. 340-382.

Ajzen, I. (2001), “Nature and operation of attitudes”, Annual Review of Psychology, Vol 52 No. 1, pp. 27-58.

Anzman-Frasca, S., Savage, J.S, Marini, M.E., Fisher, J.O. and Birch, L.L. (2012) “Repeated exposure and associative conditioning promote preschool children's liking of vegetables”. Appetite, Vol. 58 No. 2, pp 543-553.

Bandura, A. (1977), Social learning theory, Prentice-Hall, New Jersey, NJ

Bellak, L. and Abrams, D.M. (1997), “The Thematic Apperception Test, the Children's Apperception Test, and the Senior Apperception Technique in clinical use, Allyn and Bacon, Boston.

Benton, D. (2004), "Role of parents in the determination of the food preferences of children and the development of obesity”, International Journal of Obesity, Vol. 28 No. 7, pp.858-869.

Berg, C., Jonsson, I. and Conner, M. (2000), “Understanding choice of milk and bread for breakfast among Swedish children aged 11-15 years: An application of the theory of planned behaviour”, Appetite,Vol. 34 No. 1, pp. 5-19.

Bernardi, J.R., Cezaro, C.D., Fisberg, R.M., Fisberg, M. and Vitolo, M.R. (2010), “Estimativa do consumo de energia e de macronutrientes no domicílio e na escola em préescolares”, Jornal de Pediatria, Vol. 86, pp. 59-64

Birch, L.L., McPhee, L., Shoba, B.C., Pirok, E. and Steinberg, L.. (1987) "What kind of exposure reduces children's food neophobia?: Looking vs. tasting”. Appetite, Vol. 9 No. 3, pp. 171-178.

Birch, L.L., Savage, J.S. and Ventura, A. (2007), “Influences on the development of children's eating behaviours: From infancy to adolescence”, Canadian Journal of Dietetic Practice and Research, Vol. 68 No. 1, pp. 1-56.

Blissett, J. (2011), “Relationships between parenting style, feeding style and feeding practices and fruit and vegetable consumption in early childhood”, Appetite,Vol. 57 No. 3, pp. 826-831.

Block, L.G., Grier, S.A., Childers, T.L., Davis, B., Ebert, J.E.J., Kumanyika, S., Laczniak, R.N., Machin, J.E., Motley, C.M., Peracchio, L., Pettigrew, S., Scott, M. and van 
Ginkel-Bieshaar, M.N.G. (2011), “From nutrients to nurturance: A conceptual introduction to food well-being”, Journal of Public Policy \& Marketing, Vol. 30 No. 1, pp. 5-13.

Bond, M., Wyatt, K., Lloyd, J. and Taylor, R. (2011), “Systematic review of the effectiveness of weight management schemes for the under fives”, Obesity Reviews, Vol. 12 No. 4, pp. 242-253.

Borgers, N., de Leeuw, E. and Hox, J. (2000), “Children as respondents in survey research: Cognitive development and response quality”, Bulletin de Méthodologie Sociologique, Vol. 66 No. 1, pp. 60-75.

Busick, D.B., Brooks, J., Pernecky, S.,Dawson, R. and Petzoldt, J.. (2008) “Parent food purchases as a measure of exposure and preschool-aged children's willingness to identify and taste fruit and vegetables”. Appetite, Vol. 51 No.3, pp. 468-473.

Cialdini, R.B., Reno, R.R. and Kallgren, C.A. (1990), “A focus theory of normative conduct: Recycling the concept of norms to reduce littering in public places”, Journal of Personality and Social Psychology,Vol. 58 No, 6, pp.1015-1026.

Clark A. (2010) "Young Children as Protagonists and the Role of Participatory, Visual Methods in Engaging Multiple Perspectives”. American Journal of Community Psychology, Vol. 46 No. 1-2, pp. 115-123.

Cooke, L. (2007), “The importance of exposure for healthy eating in childhood: A review”, Journal of Human Nutrition and Dietetics, Vol. 20 No. 4, pp. 294-301.

Donald, I. and Cooper, S.R. (2001), “A facet approach to extending the normative component of the theory of reasoned action”, British Journal of Social Psychology, Vol. 40 No. 4, pp. 599-621.

Einarsdóttir, J. (2007), “Research with children: Methodological and ethical challenges” European Early Childhood Education Research Journal,Vol. 15 No. 2, pp. 197-211.

Fishbein, M. and Ajzen, I. (2010), Predicting and changing behavior: The reasoned action approach. Psychology Press, New York.

Fiskesprell (2013). “Purpose of Fiskesprell”, available in Norwegian at: http://www.fiskesprell.no/Om-Fiskesprell (accessed 13 November 2013).

Gaumer, C.J., Arnone, C.S. and Ashley-Cotleur, C. (2013), “Child influence: Depth interviews with pre-operational child consumers and their parents”, Journal of Food Products Marketing, Vol. 16 No. 1, pp. 219-235

Grieg, A. and Taylor, J. (2007), Doing research with children, SAGE Publications Ltd., London 
Harper, L.V. and Sanders, K.M. (1975), “The effect of adults' eating on young children's acceptance of unfamiliar foods”. Journal of Experimental Child Psychology, Vol. 20 No. 2, pp 206-214.

Hendy, H.M. and Raudenbush, B. (2000), "Effectiveness of teacher modelling to encourage food acceptance in preschool children”, Appetite,Vol. 34 No. 1, pp. 61-76.

Honkanen, P., Olsen, S.O. and Myrland, Ø. (2004), Preference-based segmentation: A study of meal preferences among Norwegian teenagers, Journal of Consumer Behaviour,Vol. 3 No. 3, pp. 235-250.

Hughes, S.O., Shewchuk, R.M., Baskin, M.L., Nicklas, T.A. and Qu, H. (2008), “Indulgent feeding style and children's weight status in preschool”, Journal of Development Behavior Pediatric, Vol. 29 No. 5, pp. 403-410.

Irwin, L.G. and Johnson, J. (2005) “Interviewing Young Children: Explicating Our Practices and Dilemmas”, Qualitative Health Research, Vol. 15 No. 6, pp. 821-831.

John, D. (1999), “Consumer Socialization of Children: A Retrospective Look at Twenty-Five Years of Research”, Journal of Consumer Research, Vol. 26 No. 3, pp. 183-213

Köster, E.P. (2009), “Diversity in the determinants of food choice: A psychological perspective”, Food Quality and Preference, Vol. 20 No. 2, pp. 70-82.

Lumeng, J.C., Cardinal, T.M., Jankowski, M., Kaciroti, N. and Gelman, S.A. (2008), “Children's use of adult testimony to guide food selection”, Appetite, Vol. 51 No 2, pp. 302-310.

Marotz, L.R. (2011), “Children's dietary needs: nutrients, interactions and their role in health”. in: Kilcast, D. and Angus, F. (Ed) Developing children's food products. Woodhead Publishing Limited, Cambridge, pp. 3-25.

Marshall, D. and Atiken, R. (2007), “Putting brands in the picture: children’s drawings of their favorite things”, Asia Pacific Advances in Consumer Research, Vol. 7, pp. 268276

Marshall, D. and O'Donohoe, S. (2010), “Children and food”, in D. Marshall, (Ed.) Understanding Children as Consumers, SAGE Publications Ltd., London, pp.167183.

Melbye, E.L., Øverby, N.C. and Øgaard, T. (2012), “Child consumption of fruit and vegetables: the roles of child cognitions and parental feeding practices”, Public Health Nutrition, Vol. 15 No. 6, pp. 1047-1055.

Mitchell, G.L., Farrow, C., Haycraft, E., Meyer, C. (2013) “Parental influences on children’s eating behaviour and characteristics of successful parent-focussed interventions”. Appetite, Vol.60 pp. 85-94. 
Morse, J. M. (1991), “Strategies for sampling”,. In Morse, J.M. (Ed.), Qualitative nursing research: A contemporary dialogue, Sage, California, pp. 117-131

Moschis, G.P. (1985), “The role of family communication in consumer socialization of children and adolescents”, Journal of Consumer Research, Vol. 11 No. 4, pp. 898-913.

Nicklas, T.A., Baranowski T., Baranowski, J.C., Cullen, K., Rittenberry, L.T. and Olvera, N. (2001), “Family and child-care provider influences on preschool children's fruit, juice, and vegetable consumption”, Nutrition Reviews, Vol. 59 No. 7, pp. 224-235.

Norwegian Directorate of Health (2007), “Guidelines for food and meals in day care”, available in Norwegian at:

http://www.helsedirektoratet.no/publikasjoner/retningslinjer-for-mat-og-maltider-ibarnehagen/Publikasjoner/retningslinjer-for-mat-og-maltider-i-barnehagen.pdf (accessed 13 November 2013).

Norwegian Directorate of Health (2011), “Dietary advice to promote public health and prevent chronic diseases”, available in Norwegian at: http://www.helsedirektoratet.no/publikasjoner/kostrad-for-a-fremme-folkehelsen-ogforebygge-kroniske-sykdommer/Sider/default.aspx (accessed 14 June 2013).

Nørgaard, M.K., Brunsø, K., Christensen, P.H. and Mikkelsen, M.R. (2007) Children’s influence on and particiaption in the family decision process during food buying”, Young Consumers, Vol. 8 No. 3, pp. 197-216.

Nørgaard, M.K. and Brunsø, K. (2011), “Family conflicts and conflict resolution regarding food choices”, Journal of Consumer Behaviour,Vol. 10 No. 3, pp. 141-151.

NSD (2013), “Norwegian social science data services”, available at: http://www.nsd.uib.no/nsd/english/index.html. (accessed 13 November 2013).

OECD (2012), “Health at a Glance: Europe 2012”, OECD Publishing. Available at: http://dx.doi.org/10.1787/9789264183896-en (accessed 14 November 2013).

Olsen, S.O. (2001), “Consumer involvement in seafood as family meals in Norway: An application of the expectancy-value approach”, Appetite, Vol. 36 No. 2, pp. 173-186.

Ormrod, J.E. (2009), Human learning, Pearson Prentice Hall, New Jersey, NJ

Owen, S., Schickler, P. and Davies, J. (1997), "Food choice: How to assess attitudes of preadolescent children”, British Food Journal, Vol. 99 No. 4, pp. 148-153.

Patton, M.Q. (2002), Qualitative Research \& Evaluation Methods, Sage Publications, Inc, California, CA.Patrick, H. and Nicklas, T.A. (2005), “A review of family and social determinants of children's eating patterns and diet quality”, Journal of the American College of Nutrition, Vol. 24 No. 2, pp. 83-92. 
Pedersen, S., Grønhøj, A. and Bech-Larsen, T. (2012) “Family members' roles in healthyeating socialization based on a healthy-eating intervention”, Young Consumers, Vol. 13 No. 3, pp. 208-223

Pliner, P. (1982), “The effects of mere exposure on liking for edible substances”, Appetite, Vol. 3 No. 3, pp. 283-290.

Pramling, I. and Doverborg-Östberg, E. (1993) To understand children's thoughts - A book of methods to interview children, Pedagogisk forum, Oslo

Ritchie, J., Spencer, L. and O'Connor, W. (2005) “Carrying out qualitative analysis”in: Ritchie, J. and Lewis, J. (Ed), Qualitative Research Practice: A Guide for Social Science Students and Researchers,SAGE publications, London, pp. 219-262.

Schrodt, P., Witt, P.L and Messersmith, A.S. (2008) “A Meta-Analytical Review of Family Communication Patterns and their Associations with Information Processing, Behavioral, and Psychosocial Outcomes”. Communication Monographs Vol 75 No. 3, pp. 248-269.

Sheperd, R. and Sparks, P. (1994), “Modelling food choice”. in MacFie, H.J.H. and, Thomson, D.M.H. (Ed.), Measurement of food preferences, Blackie Academic \& Professional, London, pp. 202-226

Statistics Norway (2012). Rise in kindergarten places and employees. Available at: http://www.ssb.no/en/utdanning/statistikker/barnehager (accessed 13 November 2013).

Tuu, H.H., Olsen, S.O., Thao, D.T., and Anh, N.T.K. (2008), “The role of norms in explaining attitudes, intention and consumption of a common food (fish) in Vietnam”, Appetite, Vol. 51 No. 3, pp. 546-551.

Wardle, J., Cooke, L.J., Gibson, E.L., Sapochnik,, M., Sheiham, A and Lawson, M. (2003a) “Increasing children's acceptance of vegetables; a randomized trial of parent-led exposure”. Appetite, Vol 40 No. 2, pp. 156-165.

Wardle, J., Herrera, M.L., Cooke, L., and Gibson, E.L. (2003b), “Modifying children’s food preferences: The effects of exposure and reward on acceptance of an unfamiliar vegetable”, European Journal of Clinical Nutrition, Vol. 57 No. 2, pp. 341-348.

Zajonc, R.B. (1968), “Attitudinal effects of mere exposure”, Journal of Personality and Social Psychology Monograph Supplement, Vol. 9 No. 2, pp. 1-27.

Zajonc, R.B. (1980), “Feeling and thinking: Preferences need no inferences”, American Psychologist, Vol. 35 No. 2, pp. 151-175. 
Zartler, U. and Richter, R. (2012), “My Family through the Lens. Photo Interviews with Children and Sensitive Aspects of Family Life”, Children \& Society. Vol. 28 No. 1, pp. 42-54.

Zeinstra, G., Koelen, M., Kok F, de Graf, C. (2007) “Cognitive development and children's perceptions of fruit and vegetables; a qualitative study”. International Journal of Behavioral Nutrition and Physical Activity, Vol. 4 No. 8, pp906-914. 